\title{
Reservoir system operation using a diversion tunnel
}

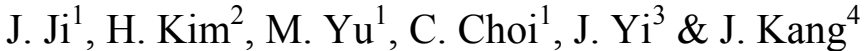 \\ ${ }^{I}$ Department of Civil and Transportation Engineering, \\ Ajou University, South Korea \\ ${ }^{2}$ Water Supply Business Division, \\ Korea Water Resources Corporation, South Korea \\ ${ }^{3}$ Department of Civil Engineering, Ajou University, South Korea \\ ${ }^{4}$ Engineering Research Institute, Ajou University, South Korea
}

\begin{abstract}
Although available water resources are limited, water demand is continuously increasing due to population increases, economic development, and additional uses, such as recreational and environmental uses. Constructing new reservoirs has traditionally been the approach to develop new water resources. However, such construction can be hampered by negative perceptions, adverse environmental effects, and opposition from NGOs to dam construction. Although Andong and Imha reservoirs are located close to each other, and they have similar hydrological and meteorological characteristics, the storage capacity of Imha reservoir is only about half that of Andong reservoir. This makes the operation of both reservoirs inefficient. This paper evaluates the effect of a diversion tunnel connecting Andong and Imha in the flood season. Water yield and spillway release reduction capability with $95 \%$ reliability were analyzed using historical daily inflows data for 30 years. By changing the reservoir operation methods, the reservoir system performance was evaluated. The system operation of the reservoirs with the diversion tunnel showed better results than the individual operation.
\end{abstract}

Keywords: flood control, reservoir system operation, diversion tunnel.

\section{Introduction}

Demand for water resources has been rapidly increasing because of population increases and economic development. Recently, demand for water necessary for recreation and environmental improvements has been also continuously 
increasing. In the case of Korea, difficulties in water resource management have been growing because approximately $70 \%$ of the mean annual precipitation occurs in the flood season (June-September) and the rainfall concentration in the flood season has also intensified recently.

The construction of new large-scale storage facilities is the optimum approach to water resource security and flood management and preparedness. Although constructing new dams is the best solution, difficulties may arise during the development of such dams because of the diffusion of negative perceptions of dam construction and opposition by environmental organizations and communities.

Multilateral measures are necessary to solve problems arising from the phenomenon of rainfall concentration. Methods of increasing the capacity to the level necessary for water supply can be divided into structural methods and nonstructural methods. Structural methods include dam raising and reservoir sediment dredging, and nonstructural methods include reservoir reallocation in flood seasons and multi-reservoir operation. Multipurpose dam operation, which is a nonstructural method, focuses on water utilization and flood control. It can be used to secure water resources by reducing the occurrence of floods and drought and related damage through the efficient distribution of water resources and operation of reservoirs.

With regard to studies on reservoir operation, the majority of past studies aimed at reducing flood damage by focusing on the operation of single reservoirs and flood control.

In contrast, most recent studies have focused on multi-reservoir operations, utilizing generalized models based on complex analyses and multilateral approaches.

Kojiri et al. [1] proposed a flood control system to calculate discharge by applying $3 \mathrm{~h}$ of old inflow rate values to fuzzy inference and analyzed the reservoir operation using four fuzzy sets. Cheng and Chau [2] studied the ability of a reservoir flood control management system developed using programming languages, such as FORTRN, C-language, and PowerBuilder, to mitigate flood damage. Xiang et al. [3] developed a module for controlling restricted flood water levels considering the uncertainty of inflows and applied it to the Three Gorges Reservoir in China. In that study, dynamic control of restricted reservoir flood water levels effectively facilitated hydroelectric power generation and increased water utilization rates without increasing the risks of flooding. To improve the rule curves for flood events using folded dynamic programming, Kumar et al. [4] collected flood data from 1958 to 1995 and applied the data to Hirakud reservoir in India that has been operated since 1956. Vonk et al. [5] used the shortage index and mean annual energy production to analyze the performance of a reservoir using an operation method of multiple purpose reservoirs. They proposed a connected simulation optimizing method for adapting to changes in water supply and demand.

In the present study, as a measure to minimize flood season spillway release with a view to preventing floods and securing water resources that are limited, the impact of a diversion tunnel between the Andong dam and Imha dam on the 
system operation of the reservoirs was investigated. The reservoir operation results were analyzed using actual discharge data for 30 years, and the effects of the separate operation of the reservoirs, the connected operation of reservoirs, and the reservoir system operation were reviewed.

\section{Present state of basins and multipurpose dams}

\subsection{Overview of basins}

Andong dam and Imha dam belong to the Nakdong river basin, which occupies approximately $25 \%$ of the territory of Korea. Andong dam is located at the uppermost stream of the Nakdong River, and Imha dam is located at the Banbyeon stream, which is the first branch of the Nakdong River. The Andong dam basin corresponds to approximately $6.8 \%\left(1,584 \mathrm{~km}^{2}\right)$ of the entire Nakdong river basin $\left(23,384 \mathrm{~km}^{2}\right)$, and the total length of flow paths in it is 31 $\mathrm{km}$. The Imha dam basin occupies approximately $5.8 \%\left(1,361 \mathrm{~km}^{2}\right)$ of the entire Nakdong river basin area, and the total length of flow paths in it is $75 \mathrm{~km}$.

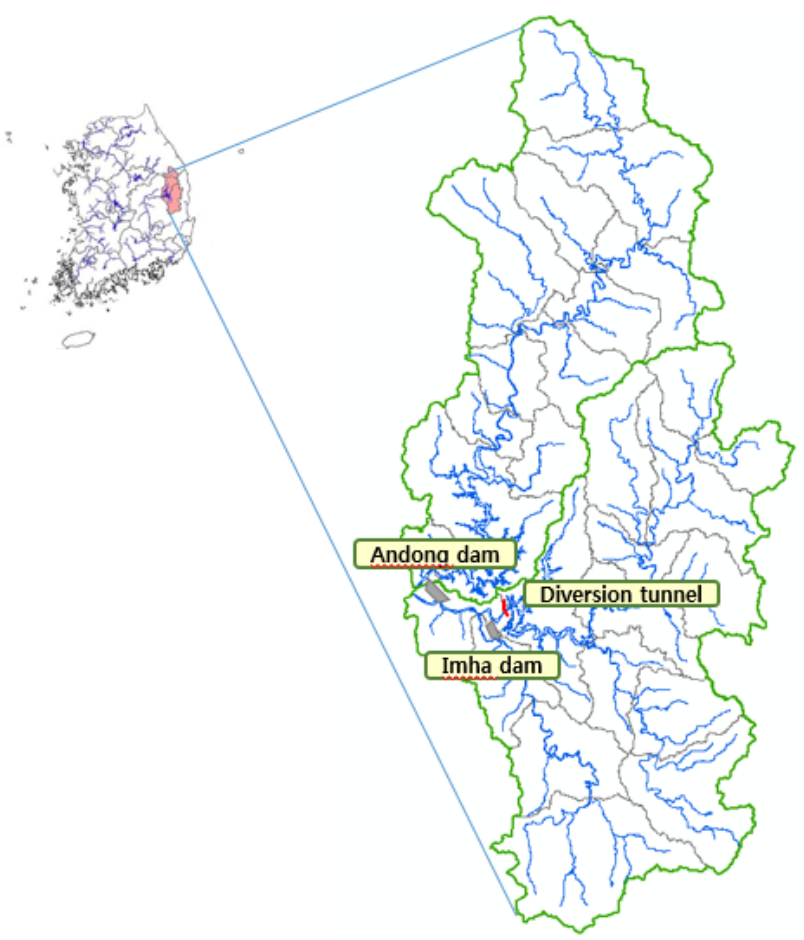

Figure 1: Diagram of the Andong dam and Imha dam basins and the diversion tunnel. 


\subsection{Specifications of the multipurpose reservoirs}

Andong reservoir is a multipurpose reservoir located in the main stream of the Nakdong River. The dam is $83 \mathrm{~m}$ high and $612 \mathrm{~m}$ long, and its total impoundment is approximately $1,248 \times 10^{6} \mathrm{~m}^{3}$. The area of the Andong reservoir basin is $1,584 \mathrm{~km}^{2}$, and the reservoir supplies $926 \times 10^{6} \mathrm{~m}^{3}$ of water to Gumi and Daegu annually. This reservoir's annual power generation is $89 \mathrm{GWh}$, and its designed maximum volume of water consumption for generation is $161 \mathrm{~m}^{3} / \mathrm{s}$. The construction of Andong reservoir on the Nakdong river system began in April 1971, and it was completed in October 1976. The aim of the reservoir was to reduce flood damage in the downstream region and to secure irrigation water, industrial water, and domestic water.

Imha reservoir was constructed $17.4 \mathrm{~km}$ above Andong-si. The dam is $73 \mathrm{~m}$ high and $515 \mathrm{~m}$ long. Its total impoundment is $595 \times 10^{6}$, and its basin area is $1,361 \mathrm{~km}^{2}$. Imha reservoir supplies $591.6 \times 10^{6} \mathrm{~m}^{3}$ of water annually, its annual power generation is $78.7 \mathrm{GWh}$, and its designed maximum volume of water consumption for generation is $119 \mathrm{~m}^{3} / \mathrm{s}$. It is a multiple-purpose reservoir constructed as part of a multipurpose water resource development project called the Master Plan for the Development of Four Major River Basins. Construction of the reservoir began in December 1984, and it was completed on December 31, 1993.

Although Andong reservoir and Imha reservoir are close to each other and have similar basin areas, the reservoir storage of Imha reservoir is only approximately $50 \%$ that of Andong reservoir. As Imha reservoir has a small water bowl, at times of similar rainfall events to those encountered at Andong reservoir, there are difficulties in flood control and in securing water utilization capacity when spillway release occurs. Therefore, this paper analyzed the effects of a diversion tunnel on the operational efficiency of both reservoirs.

\subsection{Water supply plan}

The reservoirs' planned monthly water supply volumes were divided into irrigation water, domestic water, industrial water, and instream flows. Andong reservoir's annual water supply is $926 \times 10^{6} \mathrm{~m}^{3}$ and that of Imha reservoir is $591.6 \times 10^{6} \mathrm{~m}^{3}$.

The annual domestic and industrial water supplies of Andong reservoir and Imha reservoir are $450 \times 10^{6} \mathrm{~m}^{3}$ and $363.6 \times 10^{6} \mathrm{~m}^{3}$, respectively. The annual irrigation water supplied by Andong reservoir is $300 \times 10^{6} \mathrm{~m}^{3}$, and that supplied by Imha reservoir is $13 \times 10^{6} \mathrm{~m}^{3}$. With regard to irrigation water, irrigation water consumption in the basin during the busy farming season from April to October is reflected in the planned monthly water supply volumes. Variations in the planned monthly water supply volumes are larger in Andong reservoir compared to Imha reservoir. The annual instream flow of Andong reservoir is $176 \times$ $10^{6} \mathrm{~m}^{3}$ and that of Imha reservoir is $215 \times 10^{6} \mathrm{~m}^{3}$ when the instream flow of Imha reservoir includes the volume supplied to Yeongcheon raceway $\left(4.8 \mathrm{~m}^{3} / \mathrm{s}\right)$. 
In this study, normal monthly water supply volumes were selected to analyze the effects of the connected operation (via the diversion tunnel) of the reservoirs on water supply volumes and additional discharges.

\subsection{Review conditions}

Storage capacities were calculated using the reservoir continuity equation based on the specifications of the Andong reservoir and Imha reservoir to determine discharges, additional supply volumes, power generation discharges, and spillway releases. The storage capacity of day $t$ was determined by the storage capacity and inflow of day $\mathrm{t}-1$. The discharge volume and the volume of the diversion tunnel on day $t$ and the reservoir discharge volume were obtained by applying an additional supply rate for day t to the basic planned (normal) supply volume. To determine the discharge volume that leads to reduced supply or spillway release, the calculated storage capacity of day $t$ was compared to the storage capacities that correspond to the full water level and the low water level. The power generation discharges of the reservoirs were discharged first, and any discharge volumes that occurred in excess of the maximum power generation capacity of the two reservoirs were counted as spillway release volumes (equation (1)).

$$
S_{t}=S_{t-1}+I_{t}-Q_{t} \pm D_{t}
$$

where $S_{t}$ is the storage volume on day t, $S_{t-1}$ is the storage volume on day t- $1, \mathrm{I}_{t}$ is the inflow volume on day $\mathrm{t}, Q_{t}$ is the discharge volume on day $\mathrm{t}$, and $D_{t}$ is the diversion tunnel diversion volume on day $t$.

The volume of the diversion tunnel was calculated considering the entrance/exit head losses and the friction head loss. This was considered the reservoir's inflow volume. In this case, 0.2 was used as the entrance loss coefficient, and 1.0 was used as the exit loss coefficient. The friction head loss was calculated using the Darcy-Weisbach formula, and a roughness coefficient of 0.015 was assumed. The sum of the diversion volumes of the two reservoirs through the diversion tunnel was 0 , and the diversion volume of each reservoir increased or decreased according to water movements between the two reservoirs (from Andong to Imha or from Imha to Andong). The formulas for calculating the volumes of the diversion tunnel resulting from head loss differences are as follows:

$$
\begin{gathered}
\Delta \mathrm{H}=\mathrm{W} L_{A D}-W L_{I H}=H_{e}+H_{0}+H_{f}=\frac{V^{2}}{2 g}\left(f_{e}+f_{0}+f \frac{L}{d}\right) \\
\mathrm{V}=\sqrt{\frac{2 g \Delta H}{f_{e}+f_{o}+f \frac{L}{d}}} \\
\mathrm{D}=\mathrm{AV}=\frac{\pi d^{2}}{4} \sqrt{\frac{2 g \Delta H}{f_{e}+f_{o}+f \frac{L}{d}}}
\end{gathered}
$$




$$
\mathrm{f}=\frac{124.6 n^{2}}{d^{\frac{1}{3}}}(\text { Darcy-Weisbach formula })
$$

where $\Delta \mathrm{H}$ is the water level difference between the two reservoirs $(\mathrm{m})$, $f_{e}$ is the entrance loss coefficient, $\mathrm{WH}_{A D}$ is the water level (m) of Andong reservoir, $f_{o}$ is the exit loss coefficient, $\mathrm{WH}_{I H}$ is the water level (m) of Imha reservoir, $f_{\frac{L}{d}}$ is the friction loss coefficient, $H_{e}$ is the entrance head loss $(\mathrm{m})$, $L$ is the length (m) of the diversion tunnel, $H_{o}$ is the exit head loss (m), $d$ is the diameter $(\mathrm{m})$ of the diversion tunnel, $H_{f}$ is the friction head loss (m), $\mathrm{n}$ is the roughness coefficient, $\mathrm{D}$ is the volume $\left(\mathrm{m}^{3} / \mathrm{s}\right)$ of the diversion tunnel diversion, $V$ is the flow velocity $(\mathrm{m} / \mathrm{s})$ of the diversion tunnel $\mathrm{A}$ is the cross-sectional area $\left(\mathrm{m}^{2}\right)$ of the diversion tunnel.

No diversion through the tunnel occurs when the water levels of the two reservoirs are lower than the height of the diversion tunnel and water can be moved between the two reservoirs only when the water levels of the two reservoirs are higher than the diversion tunnel. Therefore, if the water level of only one reservoir is higher than the diversion tunnel, diversion will occur until the higher water level of the reservoir goes down to the height of the diversion tunnel. If both the water levels of the two reservoirs are higher than the diversion tunnel, diversion will occur from the reservoir with the higher water level to the reservoir with the lower water level until the water levels of the two reservoirs become the same.

As both reservoirs are installed with hydroelectric generation facilities and generate hydroelectric power through the power discharge. Generation is calculated through the discharge. The power generation, $\mathrm{P}$, was calculated using equation (6), and a generator efficiency value of 0.86 and a hydraulic turbine efficiency value of 0.95 were applied to both reservoirs.

$$
\mathrm{P}=9.81 \times \gamma_{1} \times \gamma_{2} \times Q \times H \times T,
$$

where $\mathrm{P}$ is the power generation (GWh),

$\gamma_{1}$ is the generator efficiency,

$\gamma_{2}$ is the hydraulic turbine efficiency,

$\mathrm{Q}$ is the reservoir discharge volume $\left(\mathrm{m}^{3}\right)$ for time $\mathrm{T}$,

$\mathrm{H}$ is the Imha reservoir water level $(\mathrm{m})$,

$\mathrm{T}$ is the friction loss coefficient $(\mathrm{h})$.

The head loss difference, $\mathrm{H}$ (equation (7)), value was obtained by deducting the tail water level from the head water level. The low water level, which is the head water level, was determined by the average of the water levels of the two 
reservoirs at time $t$ and the next time $t+1$. The tail water level is the water level at which the water was discharged. This is usually determined by the water level of the regulating reservoir. However, in this paper, the value obtained by deducting the average value of tail water levels from the average value of forebay water levels was applied because the water level of the regulating reservoir could not be considered and the simulation was conducted focusing on main reservoirs.

$$
\mathrm{H}=\frac{1}{2}\left(W L_{t}+W L_{t+1}\right)-\frac{1}{2}\left(H W L^{\prime}+L W L^{\prime}\right),
$$

where $\mathrm{W} L_{t}$ is the low water level at time $\mathrm{t}, \mathrm{W} L_{t+1}$ is the low water level at time $t+1, H W L '$ is the full water level of the regulating reservoir, and $\mathrm{LWL}^{\prime}$ is the low water level of the regulating reservoir

The number of days of water shortage was calculated based on the low water level. Days on which the water level of the reservoir was the same as the low water level were counted as days of water shortage. That is, cases where the water level of the reservoir dropped to the low water level and could not satisfy the basic supply volume were defined as cases of water shortage, and the numbers of days of water shortage determined in this way were counted.

\subsection{Reservoir system operation}

Reservoir system operation is important when two or more reservoirs are operated simultaneously and when those reservoirs are located in series or in parallel. In such cases, the operation of one (e.g., inflow volumes and discharges) affects the operation of the other, with at the same downstream point. Simultaneous operation of reservoirs allows more efficient use of water resources than operating individual reservoirs separately.

In the case of connected reservoir operations, two reservoirs are automatically connected by a diversion tunnel. When the water level of any one reservoir is higher than the diversion tunnel, the reservoir system operation occurs automatically. However, if the water levels of the two reservoirs are lower than the diversion tunnel, the two reservoirs will be operated separately.

The system operation is a nonstructural operation mode intended to secure maximum water utilization capacity through the control of discharge volumes between the reservoirs. It can be utilized for various purposes and takes the characteristics of individual reservoirs into account to control flood peaks and to optimize flood control. Hirsh et al. [6] advised that integrated reservoir system operation has synergy effects and illustrated this through numerical experiments.

If the Andong reservoir and Imha reservoir are system operated, when a downstream target point is considered, the water volume required at this point can be satisfied when there is a water shortage in one of the reservoirs or when the other reservoir has surplus water by discharging water at the necessary flow rate. If these reservoirs are not system operated, if a water shortage occurs (a low water level is reached) in either of the reservoirs, the water demand of the target point cannot be satisfied. If the number of days of water shortage in both of the 
reservoirs is counted, each occurrence of water shortage in the reservoir will be counted in the number of days of water shortage.

Therefore, cases where system operation is in place cannot be compared with cases where it is not in place based on the number of days of water shortage.

For this reason, to compare the number of days of water shortage under system operation and nonsystem operation, the days were calculated using the concept of deficit supply. In the deficit supply method, the number of days of water shortage is not based on the concept of firm yield, which is the defined supply volume, such as the basic planned discharge volume, guaranteed to be supplied by each reservoir. Instead, it is based on the water volumes that have to be supplied by any reservoir with extra storage capacity to downstream regions.

\section{Application and results}

In this study, the results of separate-system operation when the two reservoirs were not connected and the results of connected-system operation when the two reservoirs were connected through a diversion tunnel were analyzed. In the analysis, additional discharge volumes, the number of times of spillway releases, and spillway release volumes were reviewed based on the same number of days $(n=1,077)$ of water shortage. Here, the system operation of the two reservoirs is discharging the sum of the basic planned water supply volumes of the two reservoirs by assigning the water supply volume according to the ratios of the amounts of storage of the two reservoirs (the current effective impoundment of each reservoir/the sum of the effective storage capacities of the two reservoirs). The additional supply volumes were divided into two equal parts and each part was assigned to each of the two reservoirs.

As can be seen in the tables and figures (Table 1, Table 2, Table 3, Fig. 2, Fig. 3), the largest volume of additional water was supplied during the connected operation, followed by the separate-system operation and the connected-system operation in order of precedence. The integrated reliability, which is the average reliability of Andong reservoir and that of Imha reservoir, was calculated. According to the results, the integrated reliability of the separate operation was $95.09 \%$, that of the separate-system operation was $95.51 \%$, that of the connected operation was $95.71 \%$, and that of the connected-system operation was $95.77 \%$. Therefore, the integrated reliability was improved in the connected-system operation by $0.68 \%$ compared to that during the separate operation. When the separate-system operation was conducted while the reservoirs were not connected by the diversion tunnel, $1.47 \mathrm{~m}^{3} / \mathrm{s}$ of additional discharge was possible. The number of times of spillway releases decreased by 4 compared to the separate operation, and the spillway release volume decreased by $566 \times 10^{6} \mathrm{~m}^{3}$. When the connected-system operation was conducted by connecting the two reservoirs with the diversion tunnel, $1.83 \mathrm{~m}^{3} / \mathrm{s}$ of additional discharge was possible. The number of times of spillway releases decreased by 13 in total compared to the separate operation, and the spillway release volume decreased by $933 \times 10^{6} \mathrm{~m}^{3}$. The annual total power generation increased by $1.9 \mathrm{GWh}$ 
during the connected-system operation compared to the separate operation, although this difference was not considered significant.

Table 1: Additional supply volumes resulting from system operation.

\begin{tabular}{|c|c|c|c|c|c|c|c|c|}
\hline & \multirow[b]{2}{*}{$\begin{array}{c}\text { System } \\
\text { operated }\end{array}$} & \multirow[b]{2}{*}{$\begin{array}{c}\text { Additional } \\
\text { discharge } \\
(/ \mathrm{s})\end{array}$} & \multicolumn{2}{|c|}{ Andong dam } & \multicolumn{2}{|c|}{ Imha dam } & \multirow[b]{2}{*}{$\begin{array}{c}\text { Number of } \\
\text { days of } \\
\text { shortage }\end{array}$} & \multirow{2}{*}{$\begin{array}{c}\text { Possible } \\
\text { annual } \\
\text { additional } \\
\text { supply } \\
\text { volume } \\
\left(10^{6} \mathrm{~m}^{3}\right)\end{array}$} \\
\hline & & & $\begin{array}{c}\text { Number of } \\
\text { days of } \\
\text { shortage }\end{array}$ & $\%$ & $\begin{array}{c}\text { Number of } \\
\text { days of } \\
\text { shortage }\end{array}$ & $\%$ & & \\
\hline \multirow{3}{*}{$\begin{array}{l}\text { Separate } \\
\text { operation }\end{array}$} & $X$ & - & 223 & 97.97 & 854 & 92.21 & 1,077 & - \\
\hline & 0 & - & 395 & 96.40 & 503 & 95.41 & 898 & - \\
\hline & 0 & 1.47 & 473 & 95.69 & 604 & 94.49 & 1,077 & 46.3 \\
\hline \multirow{4}{*}{$\begin{array}{c}\text { Connected } \\
\text { operation }\end{array}$} & $X$ & - & 251 & 97.71 & 690 & 93.71 & 941 & - \\
\hline & $\mathrm{X}$ & 1.00 & 272 & 97.52 & 805 & 92.66 & 1,077 & 31.5 \\
\hline & 0 & - & 406 & 96.30 & 452 & 95.88 & 858 & - \\
\hline & 0 & 1.83 & 502 & 95.42 & 574 & 94.76 & 1,076 & 57.8 \\
\hline
\end{tabular}

Table 2: $\quad$ The number of times of spillway releases and spillway release volumes during system operation.

\begin{tabular}{|c|c|c|c|c|c|c|c|c|}
\hline & \multirow{2}{*}{$\begin{array}{c}\text { System } \\
\text { operated }\end{array}$} & \multirow{2}{*}{$\begin{array}{c}\text { Additional } \\
\text { discharge } \\
(/ \mathrm{s})\end{array}$} & \multicolumn{2}{|c|}{$\begin{array}{c}\text { Number of times of spillway } \\
\text { releases }\end{array}$} & \multicolumn{3}{|c|}{ Spillway release volume } \\
\cline { 5 - 10 } & & & $\begin{array}{c}\text { Andong } \\
\text { dam }\end{array}$ & Imha dam & SUM & $\begin{array}{c}\text { Andong } \\
\text { dam }\end{array}$ & Imha dam & SUM \\
\hline \multirow{2}{*}{$\begin{array}{c}\text { Separate } \\
\text { operation }\end{array}$} & $\mathrm{X}$ & - & 26 & 45 & 71 & 2,008 & 3,064 & 5,072 \\
\cline { 2 - 10 } & $\mathrm{O}$ & 1.47 & 32 & 35 & 67 & 2,313 & 2,193 & 4,506 \\
\hline \multirow{2}{*}{$\begin{array}{c}\text { Connected } \\
\text { operation }\end{array}$} & $\mathrm{X}$ & 1.00 & 31 & 26 & 57 & 2,368 & 1,810 & 4,178 \\
\cline { 5 - 10 } & $\mathrm{O}$ & 1.83 & 31 & 27 & 58 & 2,373 & 1,766 & 4,139 \\
\hline
\end{tabular}

Table 3: Annual power generation during system operation.

\begin{tabular}{|c|c|c|c|c|c|c|c|}
\hline & \multirow{2}{*}{$\begin{array}{l}\text { System } \\
\text { operated }\end{array}$} & \multirow{2}{*}{$\begin{array}{l}\text { Additional } \\
\text { discharge } \\
\left(\mathrm{m}^{3} / \mathrm{s}\right)\end{array}$} & \multicolumn{3}{|c|}{ Annual power generation } & \multirow{2}{*}{$\begin{array}{c}\text { Annual total } \\
\text { power generation } \\
(\mathrm{GWh})\end{array}$} & \multirow{2}{*}{$\begin{array}{c}\text { Possible annual } \\
\text { additional } \\
\text { supply volume } \\
\left(10^{6} \mathrm{~m}^{3}\right) \\
\end{array}$} \\
\hline & & & $\begin{array}{c}\text { Andong } \\
\text { dam }\end{array}$ & $\begin{array}{c}\text { Imha } \\
\text { dam }\end{array}$ & SUM & & \\
\hline \multirow{2}{*}{$\begin{array}{l}\text { Separate } \\
\text { operation }\end{array}$} & $\mathrm{X}$ & - & 26 & 45 & 71 & 173.7 & - \\
\hline & 0 & 1.47 & 32 & 35 & 67 & 175.7 & 46.3 \\
\hline \multirow{2}{*}{$\begin{array}{l}\text { Connected } \\
\text { operation }\end{array}$} & $\mathrm{X}$ & 1.00 & 31 & 26 & 57 & 178.1 & 31.5 \\
\hline & 0 & 1.83 & 31 & 27 & 58 & 175.6 & 57.8 \\
\hline
\end{tabular}




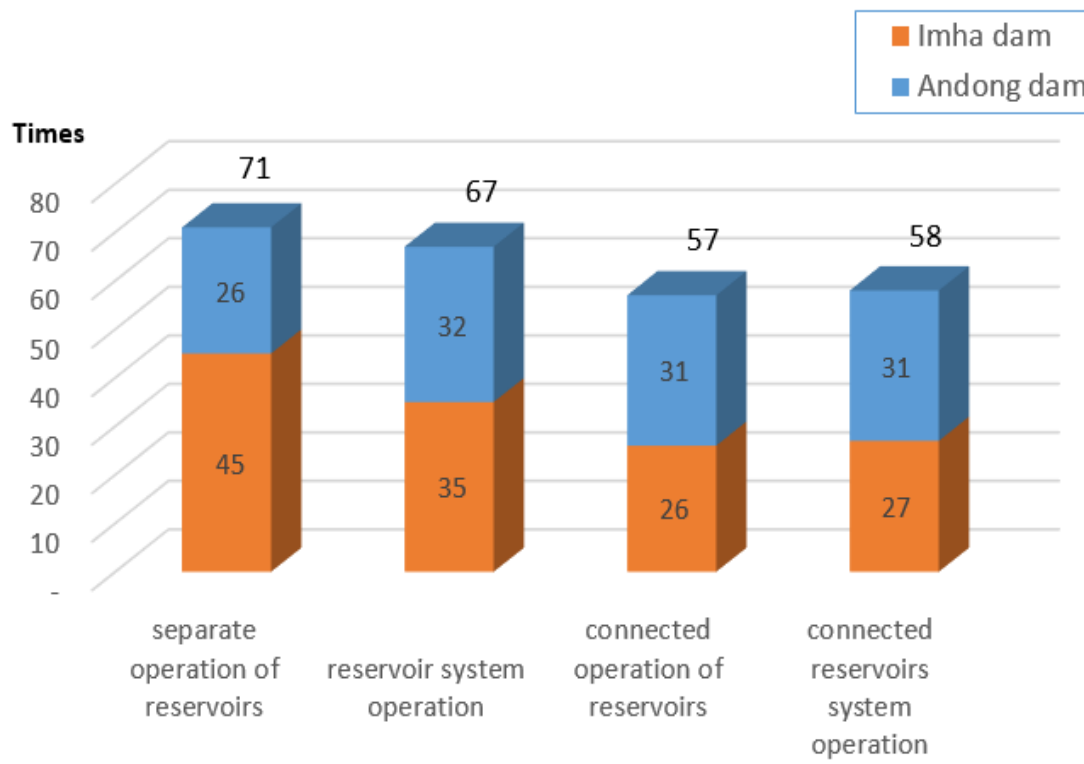

Figure 2: $\quad$ The number of times of spillway releases during system operation.

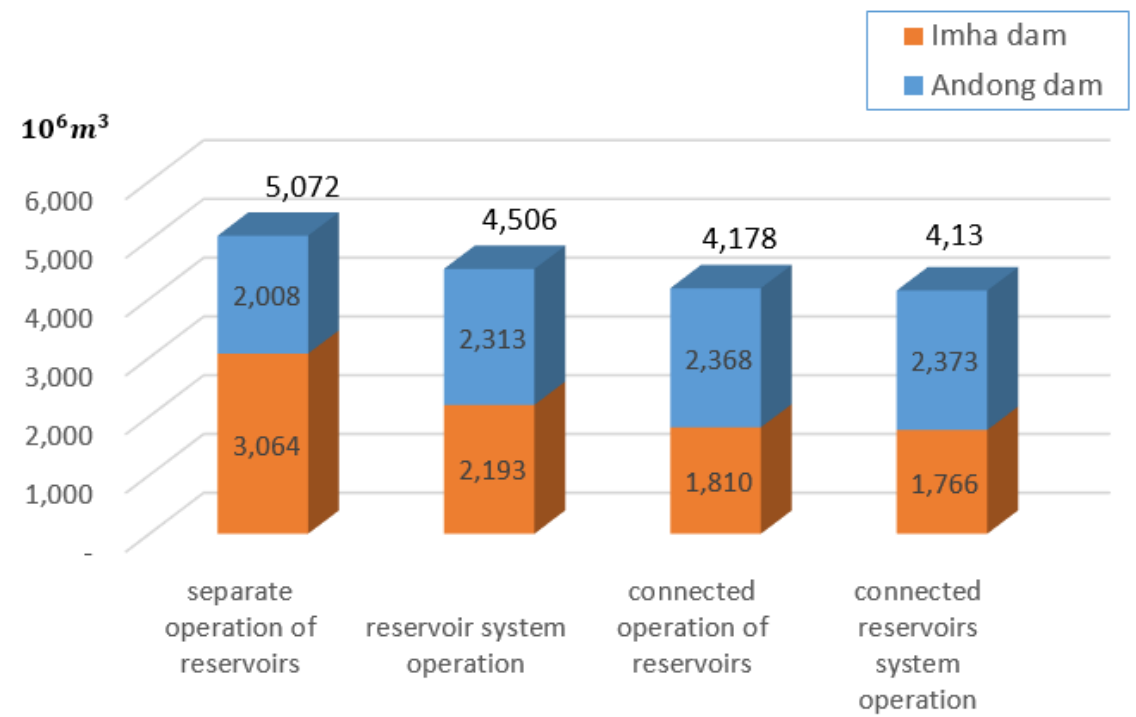

Figure 3: Spillway release volumes during system operation. 


\section{Conclusion}

In this study, the effects of the connected reservoir operation of Andong reservoir and Imha reservoir using a diversion tunnel were analyzed to prevent floods and to ensure an uninterrupted water supply during drought periods by efficiently managing the water resources that are spillway-released during flood seasons. Structural methods using a connected reservoir operation and a nonstructural a system operation method were applied. Using daily discharge data for 30 years from 1979 to 2008, daily simulations were conducted using the reservoir continuity equation, and water yields and effects of reducing spillway release volumes were reviewed based on $95 \%$ reliability.

According to the results of the analyses based on the concept of deficit supply, the number of times of spillway releases and spillway release volumes decreased the most during the separate operation of the reservoirs, followed by the reservoir system operation, the connected operation of the reservoirs, and the connected reservoir system operation in order of precedence. In addition, the possible annual additional supply volumes increased the most during the separate operation of the reservoirs, followed by the connected operation of the reservoirs, reservoir system operation, and the connected reservoirs system operation in order of precedence.

Although system operation without the diversion tunnel enabled reducing spillway release volumes and securing additional supply volumes during drought periods, larger effects were obtained when the diversion tunnel and system operation were used simultaneously. Given these results, using the diversion tunnel and system operation together is considered to result in a structurally stable connected reservoir operation.

In this study, the effects of using the diversion tunnel and the results of system operation were examined in terms of their flood season spillway release reducing effects and water supply during water utilization periods. With regard to connected reservoir operations, a comprehensive analysis of hydroelectric power generation, water quality improving effects, and economic and sociological benefits is needed to address.

\section{Acknowledgement}

This work was supported by a National Research Foundation of Korea (NRF) grant funded by the Korean government (MEST) (No 2013-065006).

\section{References}

[1] Kojiri, K., Ikebuchi, S. \& Yamada, H., Basinwide flood control system by combining prediction and reservoir operation. Stochastic Hydrology and Hydraulics, 3, pp. 31-49, 1989.

[2] Cheng, C. \& Chau, K.W., Flood control management system for reservoirs. Environmental Modeling \& Software, 19, pp. 1141-1150, 2004. 
[3] Xiang, L., Shenglian, G., Pan, L. \& Guiya, C., Dynamic control of flood limited water level for reservoir operation by considering inflow uncertainty. Journal of Hydrology, 391, pp. 124-132, 2010.

[4] Kumar, N.D., Baliarsingh, F. \& Raju, S.K., Optimal Reservoir Operation for Flood Control Using Folded Dynamic Programming. Water Resour Manage, 24, pp. 1045-1064, 2010.

[5] Vonk, E., Xu, Y.P., Booji, M. J. \& Augustijn, D.C., Adapting Multireservoir Operation to Shifting Patterns of Water Supply and Demand. Water Resour Manage, 28, pp. 625-643, 2014.

[6] Hirsh, R. M., Cohon, J. L. \& ReVelle, C. S., Gains from joint operation of multiple reservoir systems. Water Resources Research, 13, pp. 239-245, 1997. 